ANALES DE LA UNIVERSIDAD DE ALICANTE. HISTORIA MEDIEVAL, n. ${ }^{\circ} 20$ (2017-2018): 137-162

DOI:10.14198/medieval.2017-2018.20.05 I.S.S.N.: 0212-2480

Puede citar este artículo como:

Bernabeu Borja, Sandra. «La praxis política dels Jurats de la ciutat de València. Segles XIV-XV». Anales de la Universidad de Alicante. Historia Medieval, N. 20 (2017-2018): 137-162, DOI:10.14198/ medieval.2017-2018.20.05

\title{
LA PRAXIS POLÍTICA DELS JURATS DE LA CIUTAT DE VALÈNCIA. SEGLES XIV-XV
}

\author{
Sandra Bernabeu Borja \\ Universitat de València
}

\section{RESUM}

L'anàlisi detallada dels compromisos personals i institucionals assumits públicament pels Jurats de la ciutat de València, en cronologies molt concretes, permet observar quines eren les principals preocupacions del govern municipal i avaluar en elles el grau de preeminència dels interessos del patriciat urbà. El creixent nombre de competències i obligacions adquirides per aquest executiu de govern se sincronitza amb el propi desenvolupament diacrònic de l'administració municipal. Les dades contingudes en l'acta del jurament institucional dels Jurats, documentada anualment des de 1325 als Manuals de Consells (llibres d'actes municipals) ens possibilita aquest estudi de base documental que pretén mostrar quina era la pràctica política als segles baixmedievals de la principal magistratura municipal de la ciutat de València.

Paraules clau: Jurats, ciutat de València, municipi, segles XIV i XV, compromís institucional.

\begin{abstract}
The detailed analysis of the personal and institutional commitments undertaken by publicly Jurats (municipal highest authority) of Valencia, in very specific timelines, allow to observe what were the main concerns of the municipal government and evaluated them the primacy degree of the urban patrician's interests. The growing number of responsibilities and obligations acquired by the executive government synchronizes itself
\end{abstract}


diachronic development of the municipal administration. The data contained in the minutes of the oath institutional Jurats, documented annually since 1325 Manuals de Consells (municipal minutes), allows us to study basic documentary aims to show what was in centuries of practice Middle Ages the main municipal magistrates of the city of Valencia.

Keywords: Juries, Valencia, municipality, $14^{\text {th }}$ and $15^{\text {th }}$ centuries, institutional commitment.

\section{INTRODUCCIÓ}

Al llarg del segle XIII els territoris que conformen la Corona d'Aragó assisteixen a una profunda reorganització política, que va comportar el naixement del municipi en un context d'expansió econòmica i territorial. Els inicis d'aquesta municipalitat deuen relacionar-se amb el sorgiment a nivell institucional de tres magistratures: els Cònsols, els Paers i els Jurats ${ }^{1}$. Magistratures que tot i que no coincidiren en la cronologia ni totes tres es van donar en el conjunt de les ciutats i viles de la corona, suposaren el sorgiment d'una societat política en el si de les comunitats locals, és a dir d'una universitas, en un procés que va culminar amb l'adquisició d'autonomia jurídica per part de dites comunitats ${ }^{2}$.

Ara bé, aquesta autonomia jurídica no va ser concedida plenament fins que la transferència de les funcions de govern als representats locals no es va convertir en una necessitat per a una monarquia catalano-aragonesa immersa en plena conquesta militar. Conquesta que va exigir a la monarquia dirigir tots els seus esforços en recollir impostos, el que va requerir dotar d'un major nombre de competències político-administratives a les comunitats urbanes

1 Els precedents més antics foren els Cònsols, representats de la comunitat veïnal per delegació de poder d'aquesta, els seus orígens estan vinculats a poblacions de trets mercantils que gaudiren de la protecció dels comptes reis. Per la seua part, el Paer, gaudia d'una capacitat directiva atorgada per la comunitat amb la finalitat de desenvolupar activitats d'arbitratge en el si de la comunitat, naix al context de les violències feudals del segle XI, en concret al marc dels moviments de Pau i treva. Finalment, el Jurats foren creats a partir de la segona meitat del segle XIII sent la monarquia, en aquest cas, qui va transferir a aquests les funcions de govern local. Cf. NARBONA VIZCAÍNO, R., «Algunas reflexiones sobre la participación vecinal en el gobierno de las ciudades de la Corona de Aragón» en Res Publica. Revista de Filosofía Política, 17, Valladolid 2007, pp. 117-119.

2 Al voltant del concepte universitas cf. BARRIO BARRIO, J.A., «La introducción del término Universitas en las instituciones municipales del reino de Valencia», en NASCIMIENTO, AA., ALBERTO P.A., Actas del IV Congreso Internacional de Latín Medieval Hispánico, Centro de Estudios Clásicos, Lisboa 2006, pp. 13-21 
per tal de facilitar i fer més eficient la gestió de les seues finances ${ }^{3}$. Fou en aquesta conjuntura marcada pel desenvolupament de la fiscalitat i la hisenda local en la que s'insereix la consolidació al capdavant del govern municipal d'una magistratura, els Jurats, que des del privilegi de la seua creació a la ciutat de València el 1245 va gaudir de facultat per a administrar, regir i governar la ciutat ${ }^{4}$. Facultat, que tot i que no fa referència explícita a la seua capacitat normativa, en la pràctica va significar la transferència als Jurats d'una capacitat de decisió i d'acció de govern extraordinària en afers de diversa naturalesa, que afecten no sols als interessos de la ciutat de València sinó també als del territori regnícola, en tant que projecció jurisdiccional d'aquesta ${ }^{5}$.

Tot plegat aquest règim municipal creat a València, constituït pels Jurats com a executiu de govern i el Consell com un òrgan assessor d'aquests, es va difondre per tota la geografia de la corona (es va introduit a Montpeller en 1246, a Mallorca i a Barcelona -on la institució s'anomenarà consellers- en 1249, i a Saragossa en 1272) on va romandre fins a la fi del període foral. Per altra part, Jaume I mitjançant l'aplicació dels furs de València va anar expandint aquest model municipal al conjunt de ciutats i viles del Regne. D'aquesta manera, des de ben aviat Dènia, Calp, Gandia, Sueca, Segorbe, Alzira, Castelló, Morvedre, Cullera, Morella, Xàtiva, Borriana, Llíria, Olocau, Ontinyent, Cocentaina i Alpont van gaudir d'unes institucions de govern que reproduien a xicoteta

3 FURIÓ A., La gènesi de la fiscalitat municipal (segles XIII-XIV), Revista d'Història Medieval, 7, Universitat de València, València 1996, pp. 9-20. I a la mateixa revista, MIRA, J.A. i VICIANO, P., «La construcció d'un sistema fiscal: municipis i impost al País Valencià (segles XIII-XIV)»,en FURIÓ, A. (Coor), La gènesi de la fiscalitat municipal (segles XIII-XIV), pp. 135-149. SANCHEZ MARTÍNEZ, M., «El sistema fiscal de los municipios catalanes y valencianos del dominio real en la Baja Edad Media» en SANCHEZ MARTÍNEZ, M., Pagar al rey en la Corona de Aragón durante el siglo XIV, CSIC, Institució Milà i Fontanals, Barcelona 2003, pp. 427-459.

4 ALANYA, L., Aureum opus regalium privilegiorum civitatis et regni Valentie, Valencia, 1972. Privilegi núm. 18 de Jaume I, atorgat en Barcelona el 13 de Setembre de 1245. (D'ací endavant ens referirem aquesta obra amb A.O). Per altra part, els Jurats van adquirir un caràcter permanent, és a dir, irrevocable en 1266, cf. A.O., Privilegi núm., 71 de Jaume I, "De concessiones perpetus officii iuratorum ac potestate illorum" atorgat en València el 15 d'abril de 1266.

5 Al voltant de la concessió del ius estatuendi als magistrats locals, és a dir, de la capacitat legislativa dels Jurats, existeix un debat historiogràfic a la ciutat de València, mentre que Rafael Narbona el situa aquesta concessió en 1245 amb el propi privilegi de fundació dels Jurats, Antoni Furió i Ferran Garcia-Oliver el situen en 1283 amb la concessió de Pere el Gran del Privilegium Magnum. Cf. FURIÓ, A., I GARCÍA OLIVER, F., Llibre d'establiments i ordinacions de la ciutat de València, Universitat de València, València 2007, pp. 22. 
escala el model de la capital ${ }^{6}$. En 1296, al context de la incorporació del Regne de Murcia a la Corona d'Aragó, la ciutat d'Alacant -i junt a ella Orihuela, Elx i Guardamar- per un privilegi de Jaume II rebia el sistema de representació municipal constituït per Jurats i Consell, tot i que no fou fins a 1308 -dos anys després de que els territoris del Regne de Murcia foren adscrits al Regne de València- quan entraren en vigor els furs de València ${ }^{7}$.

Així doncs, pertot arreu l'amplia capacitat de govern adquirida pels Jurats, que devia ser executada sota el principi de fidelitat al rei i pel bé de la universitat, va anar concretant-se en tot un seguit de competències i obligacions d'acord amb el desenvolupament de l'administració municipal i l'adaptació a la realitat socioeconòmica de cada ciutat i vila. En aquest sentit, la historiografia ja des de Pere Jeroni Taraçona ha anat precisant les atribucions dels Jurats de la ciutat de València a partir especialment de la consulta de privilegis i furs ${ }^{8}$. Atribucions, que van ser sintetitzades ja per Ignacio Villalonga Villalba en sis grans esferes de poder: avituallament, facultats d'ordre econòmic, reformes urbanes, facultats jurisdiccionals i polítiques, instrucció i beneficència i, finalment, defensa de la ciutat ${ }^{9}$. Gairebé idèntiques competències presentarien els Jurats d'Alacant, els d'Alzira o bé els de la vila de Castelló, dels quals s'ha destacat especialment la seua facultat en matèria econòmica (gestió de la hisenda municipal, jutges en imposicions tributàries) i en l'avituallament (taxació de preus, regulació de les importacions i exportació d'aliments, etc) ${ }^{10}$.

6 NARBONA VIZCAÍNO, R., «Inicios de la organización político-institucional en los municipios valencianos del siglo XIII» en Actes del III Congrés d'Estudis de La Marina Alta (1990), Institut d'Estudis Comarcals de la Marina Alta, 1992, pp. 199-207.

7 BARRIO BARRIO, J. A. «La organización municipal de Alicante, siglos XIV-XV» a Anales de la Universidad de Alicante, Historia Medieval, 7, Alicante 1990, pp. 139-141.

8 Segons aquest autor, els Jurats tenien competència per a aconsellar al Justícia sobre sentències definitives així com ordenar la celebració de festes i processons, recaptar talles, cises i altres imposicions, disposar ordenances, regular el preu del cereal, prohibir la seua exportació fora del regne i inclòs flectar barques per a vigilar l'extracció de gra i la defensa de pirates i corsaris. Alhora tenien capacitat per impedir que es dugueren armes i cavalleries en els llocs indicats per ells, ser jutges en causes del emprius, actuar sobre l'urbanisme i procedir com a jutges de marjals i sèquies tributaries del Túria o Guadalaviar, a excepció de la de Moncada, cf. TARASSONA JERONI, P., Institucions dels furs i privilegis del Regne de Valencia, València, Del Sènia al Segura, 1976.

9 Villalonga VILlALBA, I., Los jurados y el Consejo: Régimen Municipal Foral Valenciano, Banco de València, Valencia, 1995, p. 71.

10 Per a la ciutat d'Alacant Cf. BARRIO BARRIO, J. A., «La organización municipal de Alicante, siglos XIV-XV»...p. 142; per a la vila d'Alzira FURIÓ A., I GARCIA-OLIVER, F. «La economía municipal de Alzira a fines del siglo XIV según un libro de cuentas de 1380-1381», a La ciudad hispànica durante los siglos XIII al XVI, Vol. II, Editorial Complutense, Madrid 1985, pp. 1615-1616; i per a la vila de Castelló cf. VICIANO, 
Malgrat però, la manca d'una recerca sistemàtica que analitze els orígens de l'adquisició de les competències dels Jurats impedeix posar-les en relació amb les principals problemàtiques esdevingudes en cadascuna de les ciutats i viles, en el moment en què aquestes competències foren assumides per la magistratura. El que, per altra part, ens permetria observar les diferències entre l'executiu de govern de la capital d'altres ciutats i viles mitjanes del regne, o inclòs de la pròpia ciutat de València front altres ciutats com per exemple Barcelona, Mallorca o Saragossa. En aquest sentit, una primera aproximació a l'adquisició de les atribucions dels Jurats de la ciutat de València que resulta molt il-lustrativa al respecte és l'anàlisi d'un document, l'acta de jurament institucional dels Jurats, fins el moment poc emprat historiogràficament, tot i que ja s'ha assenyalat com s'observa en ell una ampliació diacrònica de les competències de l'executiu de govern ${ }^{11}$. En aquest sentit, definir quines eren les directrius bàsiques i les problemàtiques prioritàries que devia regir la pràctica política dels Jurats de la ciutat de València en un determinat període, és el que es pretén amb la finalitat d'observar quins compromisos específics van adquirir els Jurats amb la comunitat local.

\section{EL JURAMENT PREVI A LA PRESSA DE POSSESSIÓ DE LA MAGIS- TRATURA}

\section{Un jurament institucional i públic de fidelitat i homenatge al poder reial}

Amb la renovació anual de les magistratures, que en el cas dels Jurats tenia lloc la vespra de la festa de Pentecosta des de 1266, tenia lloc el jurament institucional previ a la pressa de possessió de la magistratura. Aquest jurament en el cas de l'executiu de govern de la ciutat de València es celebrava en una cerimònia pública, que des de 1337 hi tenia lloc en la Catedral el dia de Pentecosta poc abans de la missa del Sant Evangeli ${ }^{12}$. Principalment, en

P., Regir la cosa pública. Prohoms i poder local a la vila de Castelló (segles XIV-XV), Universitat de València, València, 2008, p. 28.

11 NARBONA VIZCAINO, R., "Cultura política y comunidad urbana: Valencia, siglos XIV-XV», en Edad Media, Revista de Historia, Universidad de Valladolid, Valladolid 2013, en especial peu de pàgina $\mathrm{n}^{\circ} 10$.

12 Aquest escenari, la Catedral, va ser reivindicat els propis Jurats per acollir el seu jurament institucional al-legant que així ho feia anualment el Justícia de la ciutat. Aquesta demanda de la juraderia va ser atorgada en 1337 per Pere IV, qui els va atorgar un privilegi en el que disposava que des d'aleshores el jurament institucional que prestaven anualment tant els Jurats com el Mostassaf devia d'esdevenir en la Catedral sense possibilitat de fer-se en cap altre lloc, cf. A.O. Privilegi núm., 22 de Jaume I, "De iuramentum de iuratis et mustaçaffio annuatim in sede e non alibi prestetur" atorgat en Daroca el 22 setembre de 1337. 
aquest jurament les persones que accedien a la magistratura rendien fidelitat i homenatge a l'autoritat reial bé davant el propi monarca o bé davant el Batlle General en una cerimònia cívic-religiosa carregada de simbolisme ${ }^{13}$. Doncs, nogensmenys se sincronitzava el inici de l'any polític i el inici de l'any per als cristians amb la celebració del descens de l'Esperit Sant.

Al igual que a la capital del regne, el dia de Pentecosta els Jurats de la vila d'Alzira també feien un jurament davant el Batlle de la vila o en la seua absència davant el lloctinent del Batlle. Tot i que en aquest cas, l'escenari on es prestava dit jurament a diferència de la ciutat de València hi tenia lloc en un espai obert, la plaça major, tot i que el moment específic es repetia, doncs també hi tenia lloc poc abans de la missa del Sant Evangeli, celebrada en aquest cas a l'església de Santa Caterina ${ }^{14}$. El fet que es precise que el jurament té lloc abans d'entrar a la missa major en situa en un espai de simbiosi entre l'acte cívic i el religiós, i en conseqüència, presenta la mateixa significació que la cerimònia institucional de l'executiu de govern valencià.

Aquest jurament pot ser interpretat com una cerimònia de representació que accentuava la superioritat del poder reial en la mesura que sotmetia l'executiu del govern municipal a la institució monàrquica. Subordinació del poder municipal al poder reial que es materialitzava per exemple quan es reservava al Batlle General la capacitat decisòria sobre les eleccions ciutadanes $^{15}$. Fins i tot, segons Belenguer Cebrià, el jurament no seria més que una limitació a les àmplies atribucions atorgades als Jurats ${ }^{16}$. Fora una limitació o no, el cert és que a partir del contingut d'un dels primers capítols inserits al jurament institucional de la magistratura, s'observa que es Jurats es comprometen tant a obrar d'acord amb l'autoritat monàrquica com pels

$13 \mathrm{Al}$ respecte de la representació monàrquica durant la cerimònia del jurament, en absència del rei, cal dir que a més del Batlle General, en els primers anys de la institució també s'efectuava davant el Cúria. I en 1278 fins i tot dit jurament de fidelitat a la monarquia el feren els Jurats davant el Justícia, Cf. NARBONA VIZCAINO, R., Gobierno político y luchas sociales. Estrategias de poder del patriciado urbano. La ciudad de Valencia, I Vol., Valencia, p. 227.

14 Lacta del jurament institucional dels Jurats d'Alzira de 1451 situa l'acte del jurament a la Plaça Major mentre tocaven les campanes de l'església de Santa Caterina, de la mateixa manera que l'acta corresponent al jurament de 1492 s'assenyala específicament l'obligació que tenia la nova juraderia d'efectuar el seu jurament abans d'entrar a dita l'església. Cf. Arxiu Municipal d'Alzira, en endavant AMA, Llibres dels Actes dels Jurats e Consell 03/42, f. II; i ídem 03/81, f. II.

15 NARBONA VIZCAINO, R., Gobierno político y luchas sociales..., p. 228.

16 BELENGUER CEBRIÁ, E., Fernando el Católico y la ciudad de València, Universitat de València, València, 2012. 
interessos de la ciutat, no sempre coincidents ${ }^{17}$. En aquest sentit, conjugar els interessos de la monarquia amb els de la pròpia ciutat sembla ser la major responsabilitat adquirida, tant per la seua magnitud com per la seua complexitat. Sols cal recordar, que al context unionista (1347-1348), l'1 de juny de 1347 cinc dels Jurats juraren la Unió en el mateix transcurs del parlament d'aquesta ${ }^{18}$. Per altra part, l'objectivitat de no deixar-se influir per les motivacions personals i actuar en conseqüència amb la cosa pública, és la segona conclusió que en podem extraure del capítol.

\section{Una font de poder municipal}

Al mateix temps, al seu jurament institucional els Jurats de la ciutat de València es comprometien personalment i institucionalment a satisfer i fer observar una relació de capítols, que van anar ampliant-se d'acord amb el desenvolupament de la pròpia administració municipal així com de la realitat socioeconòmica esdevinguda en la ciutat. Així doncs, cada nou compromís ofert davant la comunitat local suposava la definició d'una nova competència i obligació adquirida pels Jurats, en la mesura que mitjançant aquest procediment se'ls atorga públicament i de forma juramentada ple poder executori.

Per altra part, alhora que començava l'any polític l'escrivà municipal iniciava la redacció de la primera acta del nou exercici, que des de 1325 ho era l'acta del jurament dels Jurats, fet que explica que des d'aquesta data el primer full dels Manuals de Consells, corresponent a l'any polític que s'iniciava en Pentecosta, siga gairebé sempre aquesta acta ${ }^{19}$. El seu caràcter

17 El capítol, introduit en 1355, deia així “...que aytant com tendrien la administració de la juraderia de la ciutat de València governarien e regirien per lo senyor rey, bé e feelment, la dita ciutat, e procurarien e administrarien tots los negocis, los quals la universitat de la ciutat dita ciutat deuria fer per qualsevol manera a profit, e utilitat del senyor rey, e de la universitat de la dita ciutat damunt dita. E donarien drets e leyals consells segons les costumes de la dita ciutat, quitats e departits de tot en tot hoy, amor, gràcia, parentesc e vehinat, e celaran totes coses que en secret e en consell, e en dictar sentència o sentències que a ells serie descubert, e totes aquestes coses sens engany, e sens art, e sens mal enginy, a bona fe, guardarien a feeltat del molt alt dit senyor rey, e que observarien en totes coses e per totes les costumes de la ciutat si deu los ajudes e los sants IIII evangelis de Déu". Cf. Arxiu Municipal de València, endavant AMV, Manuals de Consells A-12, full 1.

18 RODRIGO LIZONDO, M., La Unión de Valencia (1347-1348). Una revuelta ciudadana contra el autoritarismo real, 1 vol, Valencia, 1986, p. 213.

19 Lacta del jurament era redactada en estil indirecte, en passat i seguint sempre el mateix formulari amb un protocol (que incloïa la invocació a la divinitat, un títol corrent, una data crònica, el nom dels Jurats i la seua extracció social, l'autoritat reial present, la descripció de l'acte dels jurament i el verb dispositiu que sempre és juraren), un text (relació de capítols a que es comprometen els jurants) i un protocol final (amb la identificació del notari públic -l'escrivà municipal-i els testimonis presents). 
anual i el fet que es conserven dits manuals a València des de 1306 ha condicionat la conservació d'un total de cent cinquanta-sis actes del jurament per extens per a un període gairebé de dues centúries, el comprès entre els anys 1306 i 1500. Per tant, s'adverteix però que dels primers cinquanta anys de l'exercici polític dels Jurats, és a dir des de la data de la seua fundació en l'any 1245 fins al 1305, en sabem malauradament poc. Mentre que fins en vuit ocasions sols apareix una ressenya en la que s'afirma que els nous Jurats feren el jurament (anys 1332, 1337, 1395, 1404, 1417, 1490, 1492, 1493), divuit en què no apareix cap menció del jurament (anys 1306-1313 i de 1315-1324) i, finalment, en tretze en què simplement no s'enregistren les actes corresponents al inici de l'any polític (anys 1314, 1326, 1330, 1348, $1352,1365,1367,1400,1425,1426,1427,1483,1491)$.

D'aquest relació es pot observar, com a pesar de que el primer Manual de Consells data de 1306, no trobarem cap acta del jurament institucional dels Jurats fins a 1325. Any a partir del qual podem començar a documentar quins foren els capítols $i$, en conseqüència, els compromisos assumits pels Jurats al llarg dels segles XIV i XV. Període secular durant la Juraderia va adquirir de forma gradual fins un total de quinze compromisos, deu des quals romandran, fins i tot, més enllà de 1500 mentre que sols cincs presentaran una curta durada producte de conjuntures molt concretes ${ }^{20}$. Doncs, els capítols nascuts de problemàtiques molt particulars una vegada resoltes aquestes la seua pèrdua de rellevància va facilitar la seua supressió del jurament. Fet que, per altra part, és indicador de com el jurament s'adequa i es limita a les qüestions que vertaderament preocupaven al conjunt del govern municipal. Per altra part, front als cinc capítols que trobem al jurament de la Juraderia fins a 1400, s'ensumaran deu més al llarg de la següent centúria, el que permet observar un increment de l'adquisició de competències de l'executiu de govern a partir del segle XV. En la taula 1 es pot observar quins capítols van conformar el jurament institucional dels Jurats, en quina cronologia foren introduits o es poden documentar i quina vigència van tenir.

De la mateixa manera, des d'una perspectiva comparativa s'observa com els Jurats de la vila d'Alzira també adquirien al seu jurament institucional una sèrie de compromisos públics, el contingut dels quals respon a la realitat polític-administrativa i socioeconòmica d'una gran vila, cap del mercat

20 La publicació per part d'Amparo Felipo Ots del Jurament institucional dels Jurats de 1564, permet una anàlisi comparativa i observar la vigència d'alguns capítol fins a aquesta darrera data. Cf. FELIPO OTS, A., La oligarquia municipal de la ciudad de Valencia. De las Germanias a la insaculación, Institució Alfons el Magnànim, València 2002, pp. 29-31. AMV, Manuals de Consells A-89, ff. 3-4v. 
TAula 1: Cronologia de l'adquisició de competències dels Jurats de la ciutat de València al seu Jurament institucional entre 1325 i 1500

\begin{tabular}{|c|c|c|}
\hline Any & Vigència & Capítols \\
\hline 1325 & Almenys fins a 1564 & Satisfer els deutes de la ciutat. \\
\hline 1325 & ' & $\begin{array}{l}\text { No vendre ni alienar els murs i valls ni } \\
\text { barbacanes. }\end{array}$ \\
\hline 1334 & 1335 i 1338 & $\begin{array}{l}\text { Vetllar per mantindre en secret allò que es diu } \\
\text { en consell. }\end{array}$ \\
\hline 1355 & Almenys fins a 1564 & Regir, administrar i governar la ciutat. \\
\hline 1370 & $"$ & Fer observar els capítols sobre la guarda del vi. \\
\hline 1405 & $"$ & $\begin{array}{l}\text { Vetllar per evitar fraus en la recepció de } \\
\text { veïnatges i la concessió de cartes de franquesa. }\end{array}$ \\
\hline 1412 & Fins a 1416 & $\begin{array}{l}\text { Sobre la forma e manera d'elegir consellers i } \\
\text { Jurats en la vigília de quinquagèsima. }\end{array}$ \\
\hline 1414 & Almenys fins a 1564 & $\begin{array}{l}\text { Vetllar per a que es respecten els Capítols del } \\
\text { Quitament fets el 30-12-1414 i el 22-11-1424. }\end{array}$ \\
\hline 1419 & " & $\begin{array}{l}\text { Vetllat per l'elecció de dos clavaris i que } \\
\text { el depòsits foren en mans del clavari del } \\
\text { quitament. }\end{array}$ \\
\hline 1419 & $"$ & Sobre les vestidures institucionals dels Jurats \\
\hline 1444 & 1446 & $\begin{array}{l}\text { Visitar "personalment la baronia de Puig e los } \\
\text { lochs de Paterna, Benguazir e la Pobla" }\end{array}$ \\
\hline 1444 & Almenys fins a 1564 & $\begin{array}{l}\text { Observar que els pellers puguen tallar en certa } \\
\text { forma }\end{array}$ \\
\hline 1447 & 1458 & $\begin{array}{l}\text { Dotar econòmicament l'obra de la cambra } \\
\text { daurada }\end{array}$ \\
\hline 1459 & Almenys fins a 1564 & $\begin{array}{l}\text { Respectar les ordinacions i addicions fetes en } \\
\text { la sentència dels emprius per un acte de cort } \\
\text { de } 1459 \text {. }\end{array}$ \\
\hline 1463 & 1471 & $\begin{array}{l}\text { Respectar la pragmàtica atorgada per lo molt alt } \\
\text { senyor Rey sobre lo fet del tenir dels rossins e la } \\
\text { crida }\end{array}$ \\
\hline
\end{tabular}

Font: Manuals de Consells. 
rural comarcal ${ }^{21}$. D'aquesta manera, es documenta com mentre a 1451 el jurament de la Juraderia alzirenya estava constituït per un compromís en 1492 a més a més d'aquest hi trobem dos més. Concretament, en 1451 els Jurats de dita vila es comprometen a observar i fer acomplir les ordinacions i el capítols referents a les eleccions dels oficis i "altres coses de la dita vila segons que aquelles es contingut e ordenat". Mentre que, per altra part, en 1492 es documenta també el compromís i l'obligació dels Jurats de romandre dins de la vila i horta, o en tot cas que almenys resten en ella dos o tres membres de la Juraderia. Finalment, es comprometeren a estar personalment en la Sala de la vila cada divendres -a excepció del divendres Sant i d'altres festes, com també en cas de malaltia o absència de la vilaper a tractar les coses del comú i exigir deutes, sense donar prerrogatives a uns i no a altres ${ }^{22}$.

\section{LA CIUTAT I LADQUISICIÓ DE COMPROMISOS DELS JURATS}

Com es pot observar en l'anterior taula, mentre el jurament de 1325 comptava sols amb dos capítols, en 1405 comptava amb cinc i en 1463 la xifra havia pujat a onze. Aquest increment s'ha de relacionar amb el desenvolupament, la regulació i la major complexitat adquirida per l'administració municipal a partir de 1400. Des d'aquesta perspectiva, podem distingir tres grups de capítols en funció de la naturalesa de les causes que es van conjugar per a que foren suficientment rellevants per a exigir el compromís anual, públic i juramentat de la Juraderia ${ }^{23}$.

\subsection{Principals preocupacions econòmiques del govern municipal}

Els deutes, els capítols del quitament i la reorganització de la gestió econòmica de la ciutat desprès de la caiguda de la taula de canvis van ser els tres grans assumptes, que van marcar la política econòmica de la ciutat durant els segles XIV i XV. El fet que trobem fins a tres capítols al jurament institucional dels Jurats relacionats en aquestes causes, mostra els esforços i la conscienciació per a garantir l'aplicació de les ordenances municipals al respecte. Per altra part, el fet que aquests capítols referents al control del deute presenten una vigència de llarga durada, és a dir no són suprimits en cap moment del desenvolupament diacrònic del jurament, mostra la

21 Cf. MARTINEZ ARAQUE, En els orígens de la industria rural. L'artesanat a Alzira i la Ribera en els segles XIII-XV, València, Universitat de València, 2010, p. 1-15.

22 AMA, Llibres dels Actes dels Jurats e Consell 03/42, f. II-IIv i 03/81, f. II- IIv.

23 Cal advertir però, que el capítol de caràcter sumptuari, referent a les vestidures institucionals dels Jurats introduït en 1419 , s'escapa d'aquesta perspectiva d'anàlisi. 
persistència estructural del deute públic com ja han demostrat els estudis d'Ernest Belenguer Cebrià ${ }^{24}$.

Des d'aquesta perspectiva, els Jurats, en tant que màxim executiu de govern municipal, constituien en un principi l'autoritat responsable en matèria financera. Aquesta responsabilitat va fer que des de ben aviat els Jurats es comprometeren a "guardar los sagraments e deutes deguts per la ciutat ab obligació de ostatge, o per qualsevol manera complir e pagar a qualssevol persones, la qual cosa feeren los damunt dits Jurats" 25 . És a dir, satisfer els deutes que la ciutat havia convingut amb algun bé com a penyora i també aquells que havia contret amb particulars, això és amb els seus creditors. Doncs, des de 1320 la ciutat delegava la gestió econòmica a un canvista municipal, malgrat però, successives fallides van provocar que des de 1327 el càrrec de clavari fora ostentant sistemàticament pel Jurat en cap. Aquesta mesura, pressa al mateix consell del dia de Pentecosta, es va cristal-litzar al propi jurament, modificant lleugerament el contingut del capítol. Doncs, des d'aleshores, els Jurats es comprometeren al pagament dels deutes que els seus antecessors en el càrrec havien reconegut deure prèviament. A més a més, el Jurat primer assumiria la responsabilitat d'elaborar un llibre "en lo qual pos e meta les reebudes, dates, messions e despeses que en aquell any se convenran a fer" ${ }^{26}$. Arribada la fi de la seua Juraderia, aquest amb un mes de termini, devia de presentar les despeses i els guanys generats a la ciutat per la seua administració.

Per altra part, fins l'any 1374 els Jurats designaren directament als administradors de les imposicions de la ciutat, que a partir d'aleshores serien elets mitjançant un sorteig de redolins entre les vuit persones no electes però que foren candidates, al sorteig a Jurat, dels quals quatre seran nomenats administradors. En 1386, els Jurats junt a vint prohoms elets per ells, nominarien a una sèrie de candidats per al càrrec de Racional, tot i que tres anys després, dita votació serà secreta i participarà tot el Consell ${ }^{27}$. Aquest mateix any de 1386, després d'haver assumit en 1327 directament la responsabilitat de la gestió econòmica, els Jurats acabaran per delegar-la, creant un càrrec específic, el del clavari comú sota la seua supervisió directa.

Aquest procés de delegació s'explica òbviament per la major complexitat de les finances de la ciutat, sobretot davant la dinàmica de creixement del

24 BELENGUER CEBRIÁ, E., Fernando el Católico y la ciudad de València, Universitat de València, València, 2012, p. 77.

25 AMV, Manuals de Consells A-1, f. 233.

26 Ordenació 176, [Elecció del clavari] a FURIÓ, A., I GARCÍA OLIVER, F, Llibre d'establiments i ordinacions... pp. 170-171.

27 NARBONA VIZCAINO, R., Gobierno político y luchas sociales... pp. 148-152. 
deute que va experimentar la ciutat durant les dècades posteriors. Doncs, la ciutat va poder fer front a les seues creixents necessitats econòmiques a través del finançament a partir del endeutament sistemàtic i sostingut que li proporcionava l'emissió de deute públic a través del censal. La generalització d'aquesta forma de préstec va comportar el sorgiment d'una la claveria de censals, que reflexa amb exactitud el pagament dels interessos per capital que prestava el municipi a inversors particulars de deute públic. El problema era que la gran quantitat de carregaments va fer insostenible el pagament d'unes pensions, que sols es redimien amb la devolució de la quantitat prestada.

Així doncs, la necessitat de fer front a la crisi de les taules de canvistesbanquers privats en constant fallida i de protegir les finances municipals va donar lloc a concebre la idea de crear una Taula pública. Així doncs, amb els precedents de Barcelona i Perpinyà que crearen les seues taules de canvi en 1401 i en 1404 respectivament, a petició de la pròpia ciutat va ser creada la Taula de canvi assegurada de la ciutat de València per un privilegi de Martí I, el 20 d'octubre de $1407^{28}$. En gener de 1408, el Consell municipal atorga plens poders als Jurats, advocats i prohoms expressament elegits per a què redactaren les ordenances que regirien la Taula ${ }^{29}$.

Malgrat però, en una conjuntura política marcada per la inestabilitat del interregne, la lluita de bàndols i on la Taula de canvis no havia ofert els resultats esperats, es va crear la claveria del quitament en desembre de 1413. Aquesta claveria tenia la finalitat de redimir a la ciutat d'alguns censals a partir d'un normativa, els Capítols del quitament, que organitzava la manera en què es devien amortitzar els títols de deute censal. Aquest capítols eren renovats i ampliats cada deu anys pels catorze prohoms de que disposava $^{30}$. La necessitat del compliment d'aquest capítols i la preocupació

28 CARRERAS ZACARES, S., La Taula de cambis a València:1408-1779, Ajuntament de València, València, 1957, p. 7.

29 Entre les principals funcions atribuïdes a la Taula de canvis assegurada en destaquen la reunió en ella de tots els ingressos i despeses municipals i la gestió de l'emissió o quitament del deute públic municipal. També dita Taula s'encarregava d'avançar diners per a l'avituallament de la ciutat, intervindré en la posada en circulació de moneda fraccionada encunyada pel municipi i també rebia depòsits particulars. Aquests últims garantien al municipi una solvència immediata i als creditors una sèrie d'interessos en benefici de la diversificació dels seus negocis, MAYORDOMO GARCIACHICOTE, F, La Taula de canvis: aportación a la historia de la contabilidad valenciana, siglos XIII-XVII, València, Universitat de València, 2002, pp. 15-16.

30 Sobre la clavaria del quitament BELENGUER CEBRIÁ, E, Fernando el Católico y la ciudad...pp. 34-40. Per altra part, hem d'assenyalar que al Consell del 22 de novembre de 1424 es va disposar l'obligació del clavari del quitament tinga compte de dur una doble comptabilitat, això és escriure per separat el dia dels ingressos i de les despeses, pel tal que puga ser consultat el dia que aquest tinga que passar comptes del seu 
que va generar en el si del govern municipal es constata amb el fet que ja des de 1414 els Jurats es comprometeren a vetllar pel seu compliment. Així ho expressa la clàusula al jurament institucional de 1414 "Semblantment juraren los capítols e ordenacions fets per lo dit consell, celebrat a XXX dies del mes de decembre del any proppassat, donants forma e manera de fer quitaments e quitar los càrrechs de la ciutat, e que en revocació o dispensació alcuna dels dits capitols o alcuns de aquells no consentran sots les penes alli contengudes e imposades" 31 .

Aquest capítol però s'ampliarà al jurament institucional de 1428, al precisar que a més a més, els Jurats s'atendran a respectar les ordinacions resultat de la renovació dels capítols del quitament, realitzada al Consell del 22 de novembre de $1424^{32}$. Altra renovació dels capítols va tenir lloc el 20 de desembre de 1434, on el Consell on la finalitat de la claveria és definida com “...dar forma e manera que pus fàcilment la ciutat sea descarregada e subllevada dels càrrechs en què es posada...". Alhora, també s'ordena que els Jurats com el consellers juren tenir en compte aquestes disposicions en el seus respectius juraments institucionals de pressa de possessió dels càrrec ${ }^{33}$.

Per altra part, en 1416, feta efectiva ja la desarticulació de la Taula de canvis, el Consell reunit el 3 d'abril va decidir reconduir la gestió de la fiscalitat municipal. Les dues decisions polítiques més importants sorgides d'aquell Consell constituiran la base d'un nou capítol del jurament institucional dels Jurats introduït en 1419. I que deia el següent: "Encara juraren tenir e servar una provisió de consell feta sots kalendari de tres d'abril any MCCCCXVI tocant que sia feta elecció de dos clavaris, e que los depòsits vinguen en poder del clavari del quitament" 34 . És a dir, els Jurats es comprometien personalment a que cada any s'elegirien dos clavaris i que els depòsits, que no eren més que aquells que es trobaven en poder de la

exercici al Consell (AMV, Manual de Consells A-28, f. 80).

31 AMV, Manuals de Consells A-25, f. 371. Respecte al contingut dels capítols, no hem trobat enregistrat el consell referent al 30 de desembre de 1413. Ara bé, com que els capítols sols tenien la vigència d'una dècada, el que si que trobem és el consell del 22 de novembre de 1424 (AMV, Manuals de Consells A-28, ff. 95-101), a partir del qual trobem un seguit de disposicions de diferent temàtica, des de com es finança dita claveria al sou dels propis clavaris.

32 AMV, Manuals de Consells A 29, f. 1, I quadern. El fet que s'incloïa al jurament institucionals dels Jurats 1428, quatre anys després de la primera renovació dels capítols, pot ser indica que l'ampliació dels capítol del quitament no havia estat assumida, i per tant es recorda aquesta ampliació. És necessari observar també que aquest capítol no apareixerà al jurament de l'ofici dels Jurats corresponent als anys 1429 i 1433, per causes que desconeguem.

33 AMV, Manual de Consells A-30.

34 AMV, Manual de Consells A-27, f. 119. 
recent exhaurida Taula de canvis en el moment de la seua dissolució, es transferiren a la claveria del quitament ${ }^{35}$.

En la pràctica, en aquest consell de 1416 es va crear el càrrec del clavari del quitament i el de clavari de censals, subalterns del racional encarregats de dirigir les claveries. Això significa, que abans d'aquesta data, existeixen ja de forma diferenciada les tres claveries al crear càrrecs específics per a cadascuna d'elles ${ }^{36}$. Les raons d'aquesta creació es deuen recercar en la necessitat de fer més eficient la economia municipal. Per últim, resulta interessant com al propi Consell de 1416 es disposava que aquests capítols del quitament siguen Jurats per cadascun dels càrrecs, "Ítem, que tots los sobre dits capitols sien jurats per lo consell present, e per cascuna juraderia e conselleria que haurà per fermus e servaran los capitols dessús dits..." 37 , tot i que com veiem els Jurats comencen a fer ho a partir de 1419.

Tot plegat, a pesar de tots els esforços, la ciutat no podia assumir el deute i es veia abocada al incompliment del pagament de les pensions d'uns creditors, que cal recordar entre ells estaven, en un nombre considerable, els propis membres del Consell i l'oligarquia patrícia. Aquesta dinàmica estructural serà la que explica la vigència permanent d'aquesta clàusula al jurament institucional dels Jurats, que representa si no pas les grans dificultats financeres que assolaven el municipi.

\subsection{La preocupació municipal per la defensa dels interessos de la ciutat}

Per altra part, entre els compromisos adquirits pels Jurats en destaca un grup que malgrat les diferències en quan al contingut i la cronologia tenen en comú que en ells se detecta una preeminència de la defensa municipal dels interessos de la ciutat, entre els que s'entreveuen alhora certa salvaguarda

35 Referent a l'elecció dels clavaris, cal assenyalar que el dia de l'elecció era, al igual que Jurats i consellers, la vespra de Pentecosta, i se n'extreien entre els consellers més destacats. Com tots els càrrecs públics oferien un jurament que a partir del 5 de maig de 1441 consistia en comprometre's que "no bestrauran, pagaran, prestaran ne anticiparan diners propis ne de la claveria a oficial algú de la casa de la dita ciutat". Sobre el salari d'aquests dos nous clavaris es va disposar al consell del 3 d'abril de 1416 que el clavari del censal fora remunerat amb 40 lliures mentre que el clavari comú ho siga en 60 lliures, AMV, Manuals de Consells A-26, f . 120

36 AMV, Manuals de Consells A-26, f.123v - 124. Aquesta resolució fou atorgada en el segon capítol del esmentat consell que diu així: "Ítem, sobre lo segon cap o article del dit consell fou vist e concordat que lo offici de la dita claveria general deu ésser dividit e departit en aquesta forma, que cascun any en lo temps acostumat fer elecció del clavari, fos feta elecció de dos clavaris, ço és de hun per a fer tant solament los pagaments de les pensions dels censal que fa la dita ciutat, e d'altre clavari per a fer tots los altres pagaments dels deutes e càrrechs de la dita ciutat".

37 AMV, Manuals de Consells A-26, f. 123-224v. 
dels interessos del patriciat urbà. Aquests capítols del jurament dels Jurats als que estem referint presenten tots una vigència permanent, el que permet observar el temor a la pèrdua d'avantatges -especialment de caràcter mercantils- derivats del veïnatge. En aquesta línia, es situen el capítol sobre la no alienació dels béns i els espais públics de la ciutat, el capítol de la guarda del vi, el capítol sobre la recepció de veïnatges i cartes de franquesa, el capítol dels pellers i, finalment, els capítol en què els Jurats comprometen a respectar les ordinacions i addicions fetes en la sentència dels emprius per un acte de cort de 1459.

Començant per ordre cronològic, en 1325 els Jurats adquiriren el compromís de "que no daran o establiran rambles, places, barbacanes, murs ne valls, ne alcuna altra cosa que sia del comú e a ús públich, e axí ho juraren"38. Aquesta obligació va sofrir una matisació al introduir en 1392 l'adjectiu "nous" referint-se als murs i valls, els quals diu no es podien vendre ni alienar encara que foren continuïs dels vells ${ }^{39}$. L'explicació de la diferenciació entre murs vells i nous s'ha d'entendre des de la perspectiva que des de 1356 s'havia estat construint una nova muralla per ordre de Pere el Cerimoniós, que ampliava extraordinàriament el perímetre emmurallat d'època andalusí. En aquest sentit, tot i que des de 1365 s'havien atorgat permisos de venta del mur vell, que ja havia perdut la seu funció defensiva la muralla musulmana va anar desmantellant-se especialment per ordre del Consell a partir de 1372 quan ja feia dos anys que s'havia acabat la construcció de la nova muralla ${ }^{40}$. Ara bé, sembla que vint anys després de l'autorització d'ocupar els espais de l'antiga muralla, i per tant es suposa que arribats a certs límits d'ocupació d'aquesta, es va fer necessari especificar que sota cap condició es podia alienar els murs nous, ni tan se vol aquells que foren continus dels vells.

Per altra part, si considerem els límits cronològics 1372 -quan s'ordena el desmantellament de la muralla antiga- fins a 1392 -moment que es modifica el capítol al jurament institucional dels Jurats- aquest coincideixen amb el desenvolupament d'una corrent antijueva a la ciutat de València, on hi té lloc al mateix temps una greu problemàtica, que té com a focus central l'ampliació de la jueria ${ }^{41}$.

38 AMV, Manuals de Consells A-1, f. 233.

39 AMV, Manual de Consells A-20, f. 1v.

40 CÁRCEL ORTÍ, M. i TRENCH ODENA., J., a «El Consell de Valencia: disposiciones urbanísticas (Siglo XIV)», en La ciudad Hispánica durante los siglos XIII al XVI, II, Madrid 1985, pp. 1451-1545.

41 Doncs, les obres de la jueria van generar una greu discòrdia que va enfrontar a grups oligàrquics partidaris i no de l'ampliació. Fets que van conduir a l'esclat d'autèntiques lluites de bàndols a la ciutat i on es deu contextualitzar anteriorment però el dramàtic 
Pel que fa al capítol sobre la guarda del vi, s'ha de considerar que l'extensió del conreu de la vinya junt a la millora i l'abaratiment dels mitjans de transport era vist com un perill per a la comercialització del vi local front d'altres de millor qualitat. Aquesta competitivitat va desencadenar la resposta de les autoritats locals, que pertot arreu van desenvolupar una sèrie de normatives de caire proteccionista ${ }^{42}$. En aquest sentit, el Regne de València no va ser una exempció i el mercat del vi va estar regit per una política partidària del vi d'àmbit local potenciada tant per la monarquia -per la necessitat després de la conquesta d'atraure la població i arrelar-la a la terra- com per les autoritats municipals o bé, en el seu cas, per senyors. La finalitat principal d'aquesta política, que des del segle XIII endavant es va anar desenvolupant, va ser la de restringir l'entrada de vi a la ciutat produït més enllà del territori de la seua contribució ${ }^{43}$.

Així doncs, en torn al comerç del vi va sorgir un entramat de privilegis reials i d'ordenances municipals que feren del vi local una mercaderia molt rentable per als productors en tant que gaudien d'un monopoli del mercat. Aquest procés de salvaguarda del interessos de la producció de vi local front a d'altres de millor qualitat fou instat per la monarquia ${ }^{44}$. Una

assalt a la jueria de la ciutat el 9 de juliol de 1391 en NARBONA VIZCAINO, R., «El trienno negro: Valencia 1389-1391. Turbulencias coetáneas al asalto de la judería» en En la España Medieval, 35, 2012, pp.177-220.

42 GUINOT, E., «El mercat local del vi a la València medieval», a GIRALT I RAVENTÓS, E. (coord.) Vinyes i vins. Mil anys d'història (Actes i comunicacions del III Col-loqui d'Història Agrària sobre mil anys de producció,comerç i consum de vins i begudes alcohòliques al Països Catalans, febrer de 1990), I, Universitat de Barcelona, Barcelona,1993, p. 433.

43 La ciutat de València gaudia d'un ampli terme general "entrò al terme de Murvedre, que partex ab Puçol; e entrò al terme d'Alocau, e dee Xiva, e de Bunyol e de Torís; e entrò en Munserrat; e entrò al terme d'Algezira e de Cullera.E de la riba de la mar siae e dur terme per C milers dintre e mar", a COLON, G., I GARCÍA, A., Furs de València, p. 109.

44 El primer privilegi sobre el mercat de vi el va ser atorgat per Jaume I, el 23 febrer de 1268. En aquest en establia que durant el període comprés des de la festa de Sant Miquel fins a Pentecosta, sols estava autoritzat vendre vi dins de la ciutat i dels seus barris extramurs aquell que hauria estat produit dintre d'aquesta o del seu terme general. És a dir, sols es permetia el lliure comerç de vi de juny fins a setembre, una vegada que la producció local havia estat comercialitzada després de la primera verema, el que garantia a aquesta un preu més elevat. En aquest sentit, el que es feia era assegurar a la producció local mitjançant el monopoli el comerç al gros, mentre que una vegada abastits els grans inversos es possibilitava les compres al menut d'un vi no local fonamentalment fetes pels taverners, els quals tot i la seua necessitat de comprar vi no es podien permetre fer grans inversions. És a dir, la producció del vi no local tenia grans dificultats per trobar eixida al mercat de la ciutat, doncs a part de quedar restringit a un mercat al detall tenia que conformar-se, a més a més, en vendre a un preu més baix per a l'abastiment fet als cellers. Cf. GUINOT, E., «El mercat local del vi a la València medieval, p. 434. 
monarquia que en 1283 transferiria al govern municipal plens poders per dur endavant la protecció de dit mercat, en un context on els fraus al respecte de la quantitat i qualitat del vi venut eren abundants ${ }^{45}$. Més tard, en 1324, Jaume II va cedir al Consell el càrrec del guardià del vi. Hi ha per tant una transferència del poder reial al municipal que fa del mercat del vi, un assumpte primordial dintre de l'esfera política del regne. És en aquest marc de regulació intensiva on devem contextualitzar el compromís personal i institucional dels Jurats en $1370^{46}$.

Per altra part, el fet que aquest capítol presente un caràcter permanent ens adverteix la rellevància que li conferien i la preocupació d'aquells que ocupaven les magistratures de fer acomplir la legislació vigent, que no era més que salvaguardar el privilegi dels productors locals. Això permet qüestionarnos el grau de relació entre les persones que ocupaven les magistratures i càrrecs municipals i els propietaris de vinyes, doncs es evident que almenys en les dècades posteriors a la conquesta aquests coincidirien ${ }^{47}$.

Junt al vi, altra preocupació del govern municipal hi eren les pastures i els aprofitaments comunals vinculats a elles. Des dels seus orígens els Jurats, com a màxima institució de govern executiu, adquiriren la jurisdicció de les terres destinades a usos comunals en els territoris de la contribució de la ciutat de València. Això explica que part d'aquests, quatre dels sis Jurats -tres ciutadans i un cavaller- formaren part del Tribunal dels Emprius ${ }^{48}$. Doncs, els grans avantatges fiscals atorgats al veïns de València i de la seua contribució seran la font de innumerables discòrdies, en tant que diàriament seran considerats per tothom com abusius, fins al punt de tenir-se que crear aquest tribunal. Davant aquesta realitat, el temor al frau serà una de les problemàtiques a les quals el govern municipal devia fer front. Frau que bé consistia en l'aveïnament de pastors durant un temps a la ciutat, la usurpació de terres comunals per part de senyorius veïns o bé de particulars, que tot i

45 A.O. Privilegi no 106, "de potestate concessa Iuratis et probis hominibus Civitatis examinandi et corrigendi ac observandi faciendi privilegium super facto vini".

46 El capítol deia així: "Juraren no res menys que servarien e servar farien de lur poder, $e$ aitant com al consell de la dita ciutat plauria, en special los privilegis e ordinacions feites sobre la guarda de no entrar vi en la dita ciutat que fos fora de la contribució de aquella AMV, Manuals de Consells A-15, f. 110. Malgrat però, a pesar de l'existència d'aquest proteccionisme, al llarg de l'any hi havia una sèrie d'exempcions segons el tipus de vi i el moment concret del calendari o conjuntura particular. Així doncs, per exemple a la ciutat de València es documenta que es podia vendre vi blanc en temps d'epidèmies, sempre que fora acompanyat d'una càrrega de blat per cadascuna de vi, Cf. VIDAL BELTRAN, Valencia en la época de Juan I, p. 203.

47 GUINOT, E., «El mercat local del vi a la València medieval»... p. 433.

48 NARBONA VIZCAÍNO, R., Gobierno político y luchas sociales... p. 147. 
ser de viles reials veuen aquests privilegis dels veïns de la ciutat de València i de la seua contribució excessius i intenten posar remei.

És en aquest context de desavinences en torn a les pastures, on devem incloure el compromís adquirit pels Jurats de 1405, on juren que en la recepció de veïnatges i cartes de franquesa observaran els furs publicats en 1403 pel rei Martít ${ }^{49}$. En concret, el capítol fa referència a la Sentència dels Emprius, publicada en les Corts el 28 de setembre de 1403, on s'estableixen una sèrie de disposicions que intenten definir els procediments en cas de plausibles conflictivitats relacionades amb les pastures i al vedat de la ciutat de València i de la contribució. La novetat que realment aporta dita sentència, ja que realment suposava l'elevació a fur del privilegi atorgat per Joan I en 1367, és la creació d'un tribunal d'apel.lació. Per altra part, es d'observar que el capítol III de dita Sentència, "que'ls Jurats, en lo començament de lur offici, juren", s'estableix el capítol que anualment deuran comprometre's a complir els Jurats ${ }^{50}$. També al capítol VIII de la mateixa, "que’ls Jurats juren", es disposa que els Jurats al començament del seu ofici es comprometen a executar bé cadascun dels capítols que conformen dita Sentència.

En aquesta mateixa línia, en 1459 els Jurats es comprometen novament a respectar la Sentència dels Emprius amb motiu de la seua ampliació en un acte de cort aquest mateix any. En aquest cas el capítol diu així: "Ítem, encara juraren servar e tenir les ordinacions e addicions derrerament en la sentència dels amprius per acte de cort fetes en les Corts derrerement celebrades en la present ciutat per lo molt alt senyor Rey en l'any present" ${ }^{\text {51 }}$. La insistència permanent en respectar la Sentència representa una major accentuació de la política

49 El capítol deia el següent: juraren que en la recepció dels veynatges e concessions de cartes de franquea dels novells veyins, servaran, e servar faran, les coses e maneres que per furs nous del alt rey en Martí, senyor nostre, són estatuïdes e ordenades sobre los fets dels amprius, e esquivaran tota frau e ficció, e no reebran los veynatges sinó solament d'aquells qui verdaderament e sens ficció, veuran e coneixeran, e sabran, de tot lur poder, volen ésser e fer-se, verdaderament e sens tota ficció o frau, veyins de la dita ciutat e dels lochs de la contribució d'aquella, e volran jurar en lur poder tenir e haver domicili, habitació, estatge e capmaior, ab muller, sin ha, e ab la maior e gran part de sos béns mobles, que no sien mercaderies almenys per VII anys cotinuus aprés que la dita franquea li serà liurada, e que en los anantaments execucions e procediments que faran en los fets dels amprius segons forma dels capitols ordenats sobre aquelles per lo dit senyor Rey se hauran bé e leyalment, e esquivaran tota frau e tot engan que si puxa fer o esdevenire totes aquestes coses a bona fe si Déu los ajud e los sants evangelis d'aquell”, Cf. AMV, Manuals de Consells A-22, f. 348 .

50 COLON, G., I GARCÍA, A., Furs de València.., p. 122.

51 AMV, Manuals de Consells A-36, f. 170. Sobre el contingut de dit acte cort de moment no estem en condicions de saber el que deia, ja que ens ha resultat impossible consultar la font primària. 
control sobre la població desenvolupada pel govern municipal amb dues finalitats interrelacionades: evitar el frau i, en conseqüència, salvaguardar els privilegis i franqueses que gaudeixen els veïns de València i de la seua contribució. El que al remat suposa garantir la pervivència del monopoli d'aquests veïns (productors de carns, productors de llana...) front als que no ho són.

De naturalesa completament diferent, en tant que derivada de la facultat dels Jurats de controlar els processos productius de les manufactures, és el compromís adquirit pels Jurats a partir de 1444, en el que juren vetllar per a què és complisquen els Capítols dels Pellers. Aquests atorgats pel Consell el 30 de setembre de 1443, mostren com la voluntat de les instàncies de govern és assegurar-se que els pellers pugen tornar a tallar draps, però sota un estricte control municipal. En aquest sentit, s'estableix que "ningun peller o altra persona volent usar el ofici de peller no compre o talle drap o staig per fer formes" 52. A més a més, les disposicions que segueixen giren al voltant bàsicament des tres aspectes: l'enregistrament a la Taula de la cisa de qualsevol acció que afecte al drap; Protegir la identitat del drap, o peces d'aquest, fet a la ciutat o a la seua contribució, i finalment, la no intromissió dels pellers en activitats pròpies d'altres oficis. Per altra part, la decisió d'ordenar aquests capítols ve precedida per la queixa d'alguns perayres de la ciutat de València, de la qual es fa resol el Consell el dia 14 d'agost d'aquest mateix any, que objecten que el seu ofici era "en penit de perdició" 53.

Com es pot deduir dels propis capítols, hi havia un malestar social entorn als pellers, que solien oferir productes de baixa qualitat i, per tant, molt barats, el que els permetia obrir-se pas en les economies domèstiques ${ }^{54}$.

52 El capítol deia: "Juraren més avant que executaran, e executar faran, complidament $e$ de fet, to pellers que puxen tallar en certa forma, e de aquelles o alguna part de aquelles no faran gràcia, relaxació o remissió alguna directament o indirecta”, AMV, Manuals de Consells A-33, f. 2. I els capítols dels pellers es troben al AMV, Manuals de Consells A-32, f. 163-164v.

53 Més en concret, el detonant d'aquesta nefasta conjuntura que afectava l'ofici, segons ells, havia estat motivada per la dolenta situació que vivien els seus clients assidus, els drapers i els pellers. Dels primers es diu que pateixen un greu empobriment a causa del seu endeutament en no haver pogut satisfer les seues compres de draps, mentre que dels segons es destaca que, a diferència del que ocorria abans, tenien prohibit tallar draps. Davant aquesta realitat, al remat la solució que proposen dits perayres consistia en què el Consell autoritzarà de nou tallar draps i robes als pellers sota certes condicions, AMV, Manuals de Consells A-32, f. 150v-151.

54 Lofici de peller consistia bàsicament en compra-venta de robes o draps vells, encara que sovint també reparaven peces de roba i inclòs roba de la casa a partir dels usats o simplement milloraven aquests i després els venien com a nous. Eren segons Juan Vicente Garcia Marsilla els vertaders especialistes del mercat de segona mà, cf GARCIA 
Òbviament, els trets dels seus productes suposaven una competència de mercat per als oficis relacionats amb la indústria tèxtil, que normalment oferien productes d'alta i mitjana qualitat, que per altra part eren els que suportaven les cises municipals i les generalitats de la Corona. D'aquesta manera, els pellers amb els seus productes solien eludir els impostos que requeien sobre el món de la producció tèxtil. Aquest problemàtica havia envoltat l'ofici de pellers des de mitjans del segle XIV i continuava viva a la València de la primera part del quatre-cents, de fet al Consell de 3 d'abril de 1436 davant del malestar manifestat per alguns drapers de la ciutat es va prohibir als pellers reparar peces de roba i forrar-les per a més tard vendreles ${ }^{55}$. Fet, que per altra part explica el malestar manifestat pels perayres i la publicació, posterior dels capítols els pellers.

Enllaçant en aquest context, també hem de situar altre greuge al voltant de la pelleria, l'associació del desenvolupament de dit ofici amb un col-lectiu determinat, els conversos. Doncs a partir de la prohibició de 1436, es va originar un feble discurs de caire xenòfob a la ciutat de València que vinculava els perjudicis que provocaven certes pràctiques dels pellers amb el fet que la majoria d'ells foren conversos. Ara bé, aquesta corrent d'opinió de l'època s'ha d'entendre com una manera més de desprestigiar als pellers, que si no pas com un element de marginació contra els conversos. És a dir, en cap cas es déu posar en relació aquest fet aillat amb les mesures segregacionistes que tingueren lloc en aquest context en altres ciutats de la Corona d'Aragó ${ }^{56}$, com per exemple a Saragossa on els jueus tenien prohibit exercir l'ofici de teixidors de llana de "paratge" 57.

Amb tot, la crisi de la manufactura tèxtil va provocar com veiem una sèrie de tensions entre els diferents oficis afins a la mateixa rama, que es resolien amb la intervenció directa de l'executiu de govern. És a dir, els Jurats tornaven a tenir en les seues mans la capacitat d'arbitrar i, per tant, de donar prevalença els interessos de sectors econòmics concrets de la ciutat. De fet, com veurem més avant, la política intervencionista dels Jurats en el món de les manufactures tèxtil els dura a donar ajudes superiors a la importació del

MARSILLA, J.V., «La vida de las cosas. El mercado de objetos de segunda mano en la Valencia bajomedieval», al Col-loqui internacional Pautes de consum i nivells de vida al món rural valencià, 18-20 de setembre de 2008, Universitat de València. p. 31.

55 NARBONA VIZCAÍNO, R., Los conversos en la Valencia del siglo XV (1391-1484). Fundamentos de su integración y de su discriminación urbana: proyecto de investigación, València Reproexpres, Valencia 2010, pp. 96-103.

56 NARBONA VIZCAÍNO, R., Los conversos en la Valencia del siglo XV (1391-1484).... pp. 96-103.

57 BLASCO MARTÍNEZ, A., «Presencia i discriminación de los judíos en la elaboración de tejidos», en Aragón en la Edad Media, 19, pp. 63-82. 
gra sicilià, en una època de sobre abastiment, amb tal de col-locar després els draps valencians en el tràfic internacional ${ }^{58}$.

\subsection{Problemàtiques concretes, compromisos específics}

Per altra part, el tercer grup de capítols del jurament el constitueixen un seguit de compromisos que van ser adquirits pels Jurats durant un breu espai de temps, quatre o cinc anys. La brevetat de la seua vigència s'insereix en estar íntimament vinculats a esdeveniments puntuals, per tant generaren únicament preocupacions temporals al govern municipal.

Entre aquests capítols, en primer lloc, destaca el introduit en 1334 pel qual els Jurats adquiriren l'obligació de vetllar perquè les deliberacions fetes en el Consell per qualsevol persona foren confidencials i en cas contrari aplicar la sanció establerta ${ }^{59}$. Al respecte d'aquest compromís, es d'observar que els Jurats ja gaudien d'aquest dret des del privilegi de la seua fundació, doncs inclòs en aquest s'especificava que se'ls permet guardar secret tant si han fet jurament com si no ${ }^{60}$.

Per altra part, que el govern municipal va publicar sistemàticament ordenances reiterant el dret a la confidencialitat dels assumptes tractats en assemblea. Així per exemple, l'1 de desembre de 1325 el Consell va disposar que allò que es tractarà en Consell no poguera ser revelat per ningú, i en cas contrari al detractor se li aplicaria la següent sanció, que no era excloent per als Jurats o consellers: no podia ser convocat per a la resta de Consells, perdria el seu ofici i perdria el dret a desenvolupar en un futur cap mena de càrrec en l'administració municipal de la ciutat. Aquest establiment fou ratificat en setembre de 1327, junt altra clàusula que prohibia als missatgers informar al rei o al seu primogènit sobre els afers de la ciutat, és a dir, que foren discrets en la informació que proporcionaren aquests reduint-se exclusivament a comunicar allò que se'ls hi havia manat. Altra disposició en la mateixa direcció és la prohibició de que un oficial reial o de la seua casa puga ser elegit en un ofici municipal, mesura amb la

58 CRUSELLES, E. CRUSELLES, J. Mª i NARBONA, R., «El sistema de abastecimiento frumentario de la ciudad de Valencia en el siglo XV: entre la sublevación pública y el negocio privado» en La Mediterrània àrea de convergència de sistemes alimentaris (segles V-XVIII) (XIV Jornades d'Estudis Històrics Locals, 29 de novembre al 2 desembre de 1995), Palma, pp. 305-332.

59 "Item, que servaran lo stabliment feyt pel consell de la ciutat contra aquell o aquelles qui dexelaran o descobriran algunes coses que en consell seran dites per qualsevol persona dels quals coses per alcú serà request ésser tengut secret" AMV, Manuals de Consells A-31, f. 1.

60 A.O., Privilegi núm. 18 de Jaume I, atorgat en Barcelona el 13 de Setembre de 1245. 
qual s’intentava evitar la transferència de informació entre dues autoritats, la reial i la municipal ${ }^{61}$.

En aquest sentit, guardar secret de les deliberacions dels membres del govern envers les autoritats reial va ser una preocupació el suficientment rellevant als anys 1334, 1335 i 1338 com per a incloure-la al jurament institucional dels Jurats, el que possiblement suggereix una vinculació entre aquest compromís amb la Guerra de la Unió de València (1347-1348).

Gairebé una centúria després, altre compromís que personalment adquiriren els Jurats fou el d'observar el compliment d'una ordenança del consell del 17 de març de 1412, en la qual s'establia un nou sistema d'aprovisionament de consellers i Jurats introduït a les Corts Generals de 1402-1403 per Martí62. El sistema d'aprovisionament al que es referia era el mètode de redolins amb una potenciació de l'atzar, el que significava en la pràctica l'eliminació de la capacitat de decisió al conjunt d'extracció ciutadana en el nomenament d'aspirants a la magistratura de Jurats.

Resulta interessant com en la propia acta del Consell de 1412 al que estem fent referencia, s'adverteix que la causa que va motivar a Martí I a fer aquestes disposicions va ser “... a fi que el regiment públic de aquella (ciutat) no pogués èsser apropriat a alguns linatges de persones més que a altres, de que experiència ha mostrat que en esta ciutat de gran temps ença són estats seguits molts mals inconvenients e danys irreparables..."63. Malgrat però, com es pot observar aquesta disposició de Martí no va entrar en vigor fins als moments finals dels Interregne i no es va prolongar més enllà de 14 de maig de 1418, moment en què fou substituïda per un altre mètode. Amb tot, la seua cronologia 1412-1418 compren un període caracteritzat per la inestabilitat política i la lluita de bàndols a la ciutat de València ${ }^{64}$, fet que va motivar la seua

61 Ordenança 197 "De tenir secret ço qui's fa en consell" i ordenances 235 "Ordinament del secret a tenir per Consell"; 236 "Ordinacions fetes per causa del regiment de la ciutat"; 237 "que nengun missatger qui serà tramés al senyor rey no parlen ni parlar facen de lurs afers ne d'altres ab lo senyor rey e son primogènit, ni empetren altres coses sinó per los fets que hi seran tramesos" i, finalment, l'ordinació 238 "que nengun oficial del senyor rey o de casa sua escrit en ració no sien elets en oficis de la ciutat" a FURIÓ, A., GARCIA-OLIVER, F., Llibre d'establiments i ordinacions..., p. 184 i pp. 216-219, respectivament.

62 El capítol deia així: Encara més, juraren que tendran e servaran l'estatud e ordinació fets per l'honorable consell de la dita ciutat, celebrat sots kalendari de XVII dies de Març proppassat, donants manera e forma de elegir cascun any en la vigília de cinquagèsima consellers e Jurats de la dita ciutat, e que en revocació o dispensació alcuna del dit statud o capitols alcuns de aquell no consentran sots les penes allí contengudes e imposades" AMV, Manuals de Consells A-25, f. 42.

63 AMV, Manuals de Consells A-25, f. 2.

64 NARBONA VIZCAINO, R., Valencia, municipio medieval...., p. 48. 
inclusió al jurament institucional dels Jurats durant quatre exercicis politics, 1412-1416.

Per altra part, la jurisdicció senyorial que exercia la ciutat de València sobre la baronia del Puig i els llocs de Paterna, Benaguatzil i la Pobla va fer que durant el període comprés entre 1444-1446, els Jurats es comprometeren a visitar-les almenys una vegada a l'any ${ }^{65}$. La petició de visitar aquest territoris de reialenc que foren transferits a la ciutat com a penyora dels préstecs atorgats a la monarquia ${ }^{66}$, es relacionen amb els "...grans desordres que per los dits oficials, habitants e altres hi eren stats fets..." i que "es continuaven cascun jorn en total destrucció del dit loch". Malgrat però, no estem en disposició de saber quins eren aquests "grans desordres" esdevinguts a que es referia Galceran de Montsoriu, Jurat de València, en $1443^{67}$. Ara bé, el fet d'aquest compromís personal i institucional dels Jurats en visitar aquests llocs, almenys durant tres anys, evidència una situació de preocupació del govern municipal alhora que es testimoni que fins el moment la ciutat no s'havia encarregat d'exercir fermament la seua jurisdicció en aquells llocs. Amb tot, davant una conjuntura d'inestabilitat, la presència allí dels Jurats de la ciutat de València era reivindicada per posar fi als conflictes existents.

Per la seua part, en 1447 els Jurats es comprometen a finançar l'última fase de les obres de la Casa de la Ciutat, això és continuar amb la construcció de la Cambra Daurada ${ }^{68}$. En la pràctica es comprometen a reservar 5.500

65 El capítol deia "Juraren encara de visitar personalment la baronia del Puig e los lochs de Paterna, Benaguatzir e la Pobla almenys una vegada en lur any juxta lo consell general celebrat en la Sala de València a XIIII d'agost de any MCCCCXXXXIII". AMV, Manuals de Consells A-33, f. 1.

66 La jurisdicció de la ciutat de València sobre el Puig té el seu inici en 1364, any en que Pere IV com agraïment a la ciutat al context de la guerra amb Castella (1356-1369), li la entrega a perpetuitat -junt a les viles de Morvedre i Cullera- cf. VIDAL BELTRAN, E., València en època de Juan I...Ibídem., p. 240. Per la seua part, la senyoria de la ciutat de València sobre els llocs de Paterna, Benaguatzil i la Pobla té el seu origen al contracte de Paterna, resultat del quantiós préstec (275.000 sous atorgat per la ciutat de València a Alfons el Magnànim, el 14 d'octubre de 1430, en una conjuntura en la que el Consell xifra el deute reial amb la ciutat en 831.931 sous cf. KÜCHLER: W. Les finances de la Corna d'Aragó (Regnats d'Alfons IV i Joan II), Edicions Alfons el Magnànim, València, 1997, pp. 93 i 382-395.

67 AMV, Manuals de Consells A-32, f. 154.

68 El capítol deia "...en virtut de un provisió de consell en lo dia de hir feta, que per tot lur poder continuaran, e continuar faran, la obra de la cambra daurada, tro sia acabada entregament e en aquella, e encara en lo pahiment de la sala maior de la dita ciutat despendran, $e$ despendre faran, almenys tro en cinch milia cinchcents sous moneda reals de València cascun any, e noresmenys, despendran, e despendre faran, a obo de enderrocaments de barandats los qual sien tenguts fer en virtut del dit jurament per embillement de la dita ciutat almenys tro en deu milia sous de la dita moneda cascun any". AMV, Manuals de Consells A-34, f.1. 
sous anuals únicament per al paviment de la sala major, construit amb marbre de Portaceli, les quals no van ser col-locades fins a març $1448^{69}$, possiblement quan es faria efectiva la primera dotació econòmica. Per altra part, també es comprometeren al finançament de 10.000 sous més en concepte d'enderrocament de barandats existents.

En aquest sentit, s'estableix que els Jurats tinguen entre les prioritats dels sues quefers quotidians, els de concloure les obres de la Casa de la Ciutat, un lloc que va esdevenir en símbol del govern i com a tal en centre de poder de la ciutat, el que va motivar que fora objecte de continues modificacions que recercaven projectar una imatge de magnificència dintre del conjunt urbà.

Així doncs, en funcionament des de 1342, l'edifici original que s'havia estat construït des de 1311 -en què Jaume II atorga els terrenys- fou ampliat el 1376 pel mestre d'obres Bernat Boix, el qual va constituir la Sala del Consell o dels Jurats a partir de la compra de noves parcel.les de cases. Fou en el Consell del 18 de juliol del 1376, moment en què es va decidir fer dita ampliació de l'edifici, quan es va establir que seria el govern municipal l'encarregat de costejar les obres i els Jurats els encarregats d'escollir als mestres d'obres. A partir d'aleshores, les intervencions en la Casa de la Ciutat estarien destinades a enriquir l'ornament de les distintes estances. És en el marc d'aquesta pretensió estètica, en el qual en 1418 el Consell decideix posar fi a les obres d'una nova estança que albergaria les reunions dels Jurats, motiu pel qual es pretenia dotar de la major sofisticació decorativa possible. Com és evident, aquesta obra es va anar dilatant en el temps, possiblement per les altes despeses que suposava i el finançament intermitent fet pel propi govern. Les actes municipals ens informen de les fases de la seua construcció, així doncs segons ha testimoniat Amadeo Desfilis a partir de l'estudi d'aquestes, gran part de la nova sala fou realitzada fins a 1426 i que entre els anys 1442-1445 es va abordar la pintura i l'ornament de la cambra amb el sostre daurat característic, que d'ençà li donaria el nom ${ }^{70}$.

Tot plegat, en aquest capítol s'observa com davant d'una necessitat, en aquest cas posar fi a les obres de la cambra daurada que s'havien anat posposant, es recorre al compromís personal i institucional dels Jurats per intentar fer més efectiva la normativa municipal. De fet, en 1458 una vegada finalitzada l'obra aquest capítol desapareixerà del jurament, en tant que ja no existirà la necessitat de dit finançament. Per altra part, es torna a

69 SERRA DESFILIS, A., «El fasto del Palacio inacabado. La Casa de la Ciudad de Valencia en los siglos XIV y XV», en Historia de la Ciudad III. Arquitectura y transformación urbana de la ciudad de Valencia, Ayuntamiento de Valencia, Valencia, 2004, pp. 89.

70 SERRA DESFILIS, A., «El fasto del Palacio inacabado...», pp. 81-88. 
posar en relleu, com el Jurats eren els màxim responsables del municipi en les situacions de major responsabilitat econòmica, en aquest els d'assignar arbitràriament els mestres d'obres en les obres públiques.

Finalment, l'últim compromís que adquiriran els Jurats de forma temporal fou Jurats el de respectar entre 1463 i 1471 la pragmàtica reial sobre els rossins i la crida vinculada a ells. El capítol dels Jurament deia que els Jurats es comprometeren a "....servaran, e servar faran, la pracmàtica atorgada per lo molt alt senyor Rey sobre lo fet del tenir dels rocins, e crida per la dita rahó feta, segons lur servici e tenor si Déu los ajudas e los sancts evangelis" ${ }^{71}$. En aquest sentit, la preocupació tant de a monarquia com del propi govern municipal en acomplir la pragmàtica reial estava justificada, doncs nogensmenys aquesta s'insereix al marc de la guerra civil catalana (1462-1472). En aquest sentit, la pragmàtica va ser publicada pocs després començament de dita guerra, que ens condueix a un moment d'efervescència del conflicte i per tant molt delicat per a Joan II. Així doncs, d'acord amb aquesta conjuntura, s'entén que el propòsit de l'ordenança no podia ser una altre que el de garantir l'existència del màxim nombre possible de cavalls armats a la ciutat de Valencià amb la finalitat de defensar la ciutat davant possibles atacs. Doncs, això almenys és el que podem concloure d'un crida que entre diu expressament "...per proveir que en la ciutat de València hi hara multitud de rocins per poder defendre la dita ciutat en qualsevol cas de necessitat $e$ ésser suficients a ofendre los enemichs de la maiestat del senyor rey e en altra manera subvenir a les necessitats ocorrents..0." ${ }^{\prime 2}$. Òbviament, aquesta mesura alhora facilitava al rei Joan II impedir l'enviament de cavalls del territori valencià cap a les terres del nord de la Corona, evitant així la no intervenció del Regne de València en la revolta catalana.

Amb tot, s'estableix un control de la població i dels rossins en un temps de crisi política en relació al context de la guerra civil catalana a través de l'establiment de l'obligatorietat de proveir-se de rossins tots aquells que tingueren els recursos per a fer ho, així com diferenciar la condició d'aquells que tenien rossí dels que no els tenien mitjançant les vestidures de les pròpies dones. Al capdavall, els Jurats es comprometien amb aquest capítol a executar aquesta normativa que va deixar de tenir vigor en el moment que el conflicte català estava arribant a la seua fi.

71 AMV, Manuals de Consells A-37, f. 71, segon quadern.

72 AMV, Manuals de Consells A-37, f. 44v. 


\section{CONCLUSIONS}

Les àmplies atribucions dels Jurats de la ciutat de València poden concretarse en tot un seguit de compromisos que van anar evolucionant segons la conjuntura socioeconòmica i política de la ciutat, que no podem deslligar del propi desenvolupament de l'administració municipal. Així doncs, el seu jurament institucional funcionava com una manera de remarcar els assumptes prioritaris a què els Jurats devien fer front per al bon regiment de la ciutat. Assumptes que responien a les pròpies dinàmiques socioeconòmiques i polítiques en què foren creades, doncs l'existència de capítols de vigència temporal és un indicador de l'adaptabilitat del jurament a aquestes dinàmiques, així com a les problemàtiques esdevingudes en la ciutat en cada moment. Així ho demostra, la problemàtica del deute enquistada a la societat baixmedieval té el seu protagonisme a un jurament on els capítol que regulen la vida econòmica de la ciutat predominen sobre la resta. Regulació de la vida econòmica que amaga sota la defensa dels interessos de la ciutat el manteniment de privilegis a grups concrets (productors de vinya, propietaris de ramat, drapers...). 